PLEURAL EFFUSIONS

\section{OBSERVATIONS ON THE PRESENT POSITION OF} TREATMENT

BY

EDWARD T. FREEMAN, M.D., B.Sc., F.R.C.P.I.

PHYSICIAN, MATER MIISERICORDIAE hOSPITAL, DLBLIN ; CONSUlTING PHYSICIAN, COOJBE LYING-IN HOSPITAL, DLBLIN ; VISITING

CONSULTING PHYSICIAY, ROYAL NATIONAL HOSPITAL FOR CONSUMFTION, NEWCASTLE

Pleural effusions are very frequent in every kind of medical practice. By this very frequency they are important, because they must be treated by all types of physicians-tuberculosis experts, hospital physicians, and general practitioners of every degree of experience and skill. They must be treated in every kind of surroundings, from sanatoriums at one end of the scale to the patient's own room at the other. It would be well, therefore, to examine the position of treatment as currently taught and practised, to see if the best possible is being done for the large number of patients presenting this condition.

\section{SEROUS EFFUSIONS}

I propose to consider these in detail. They are potentially dangerous or are harmless. The treatment currently taught and practised is either satisfactory or leaves something to be desired. In the latter event it will be necessary to seek where the deficiency lies, and to see what measures can be proposed to improve it.

To examine the case in this manner will inevitably introduce much that is agreed and well known, but for the sake of clearness it is better to consider everything from the beginning, and to develop the argument on the assumption that no prior knowledge exists.

\section{Their Dangers}

Are serous effusions dangerous? If one excludes effusions of cardiac, renal, or malignant origin, one can start with the statement that almost all pleurisies are tuberculous, and that every effusion that begins insidiously and progresses to a large chest full of fluid is almost certainly so. It is not easy to obtain references to the after-histories of these cases, but Burrell ${ }^{1}$ states that 40 per cent. of them develop pulmonary tuberculosis. The records of the large American insurance companies, quoted by Norris and Landis, ${ }^{2}$ show that the death rate from tuberculosis of the lungs among persons who have had pleurisy within five years prior to insurance is three times the average rate for individuals without such a history. These authors, viewing the matter from another standpoint, publish four series of statistics showing the percentage rate of antecedent pleurisy in groups of cases of pulmonary tuberculosis. Their four groups total 9,362 cases, of whom 2,937 , or 31.3 per cent., had had pleurisy before the manifest development of their pulmonary lesions. In these statistics fibrinous pleurisy is not separated from effusion, which, in general, is the more serious manifestation. It should be remembered that the pleura is invaded from the lung, and that the disease, active or not, already exists in the pulmonary tissue when a pleural effusion has formed. I believe that these figures and considerations prove that, in dealing with a pleural effusion, one is dealing with a serious condition, and that anything that will lessen the risk of subsequent active pulmonary tuberculosis is a matter of fundamental importance.

\section{TREATMENT}

In a fibrinous pleurisy, or in a case with a small effusion, it is usually sufficient to keep the patient in bed until the temperature settles and the fluid is absorbed and then send him to a sanatorium or adopt sanatorium regime for several months in his own house. When an effusion becomes so large that it embarrasses the heart, when the temperature will not come down, when dyspnoea or severe pain is present, or when, after three or four weeks, no sign of absorption has occurred, it will be necessary to interfere actively with the effusion, to reduce the temperature, to prevent toxic absorption, and to limit the tendency to fibrosis of the lung from organization of the effusion spreading into it.

\section{InADEQUacy of Current Teaching}

To determine what steps are recommended to students and practitioners for carrying out this interference, I consulted all the best-known English and American textbooks of medicine published in the last few years. All advise aspiration of the fluid in terms of which two examples are typical:

1. The fluid must be withdrawn slowly. The amount will depend on the quantity present, but it is safer not to exceed $1,500 \mathrm{c} . \mathrm{cm}$. Pain occurs after a certain amount of fluid is withdrawn. It is sharp and cutting; coughing occurs later, and may be severe and paroxysmal. Faintness is common, and sudden death has been recorded. Pneumothorax of slight extent often follows an exploratory puncture or aspiration.

2. Aspiration should be stopped if cough becomes troublesome, if pain is severe, or if albuminous expectoration with signs of oedema supervenes. In rare cases sudden death from pleural shock has occurred. Other risks are due to faulty technique, and comprise entrance of air into the pleural cavity from wrong connexion of the apparatus or from wounding the lung.

Of the many whom I consulted, only one author mentions what must be in the experience of everyone who has dealt with these cases-namely, that the aspiration of the fluid may precipitate the spread of an acute pulmonary tuberculosis, leading to a fatal issue in a few months. On the other hand, as the quoted examples show, all the writers stress the much rarer accidents that occasionally follow attempts at too complete evacuation of the chest, with consequent production of a high negative pressure. On this account they all recommend partial aspiration up to an average limit of $1,500 \mathrm{c.cm}$., but none of them mention the probability of basal adhesions, permanent fibrosis, and impaired expansion following the slow absorption of residual fluid standing for long periods in the base. Some authors suggest that the fluid may be replaced by oxygen, and one by oxygen and air, but rone, with the exception of those contributing to the more advanced and specialist type of textbook that does not come the way of the student or general practitioner, give any further details. Indeed, they all class a pneumothorax amongst the possible accidents of a badly conducted aspiration.

It would emerge from a consideration of the foregoing that current practice is far from satisfactory, and that the ideal method of treatment should satisfy these conditions:

1. It should cause no danger or distress to the patient.

2. It should ensure as far as possible against the spread of pulmonary disease.

3. It should aim at total emptying of the chest-to prevent basal fibrosis.

\section{Gas RePlacement}

Now there is a method which does answer these requirements. This ideal method-gas replacement-is not new, having been used by R. W. Parker ${ }^{3}$ in 1882 for the treatment of empyema, and a few years later by Potain ${ }^{4}$ in the treatment of an effusion complicating a spontaneous pneumothorax. Later, Vaquez and Achard applied it to serous pleural effusions. In recent years it has been employed regularly by most of those interested in pulmonary conditions, and has been strongly urged in several papers by Burrell ${ }^{5}$ and others for some years past. In spite of this the procedure, as we have seen, has not made much headway as a routine procedure among physicians, and is contemptuously dismissed in current textbooks intended for students and practitioners. It may be objected that it takes a long time for new methods to 
appear in bosks, and that the actual practice, at least in teaching hospitals, is in advance of current textbook advice. I do not believe this, but feel certain that the contrary is the case, and that most pleural effusions, when interfered with at all, are simply tapped by house-physicians who in many cases measure: success by the quantity of fluid obtained.

The reason for this is twofold: (1) the usual technique is moderately difficult; and (2) the dreadful shock involved by the sudden expransion of the collatpsed lung and the shifting of the mediastinum is not appreciated, in spite of occasional fatalities, many accidents, and frequent pain and distress. This lack of appreciation follows from the fact that attention has bern directed to the effusion itself, and the state of the lung within the fluid has been quite neglected and is not visualized by the physician. This also applies to the displacement of the mediastinum.

Again, the size of the chest is never considered, either in relation to the volume of fluid that may be withdrawn or the degree of pulmonary collapse that will be produced by a given volume: of fluid in chests of different capacities.

Fig. 2 shows a large chest from which 2.7 litres were removed atid replaced by 1.6 litres of oxygen, the pressitre being negative. fiig. 1 shows a small chest from which 1 litre was momoved and replaced le 750 c.com, air the pressure being positive. induction trocar, in connexion with a pneumothorax apparatus, is put into the upper part of the chest and the fluid removed as the air is run in. This is equivalent to inducing a pneumothorax plus aspiration. It is always a matter of some little trouble to induce a pneumothorax for the first time, and even in expert hands it is occasionally quite difficult. A refill into an rxisting air cavity is, however, always a simple matter. A further difficulty in a completely full chest is that the pneumothorax trocar and tubing may immediately fill with fluid. As this fluid must be returned to the chest it is essential that the whole tubing be sterilized and dried before use on wach occasion. This latter is a time-consuming and diffcult process. Furthermore, the fluid in the trocar and tubing is almost certain to produce bubleles and waterlocks, which interfere with the manometer readings. Lastly, the procedure, which can never be single-handed, involves the use of apparatus with which many physicians are not familiar.

\section{METHOD ADVOCATED}

To overcome these difficulties I have improvised an a cquipment, the basis of which is the well-known rotancla

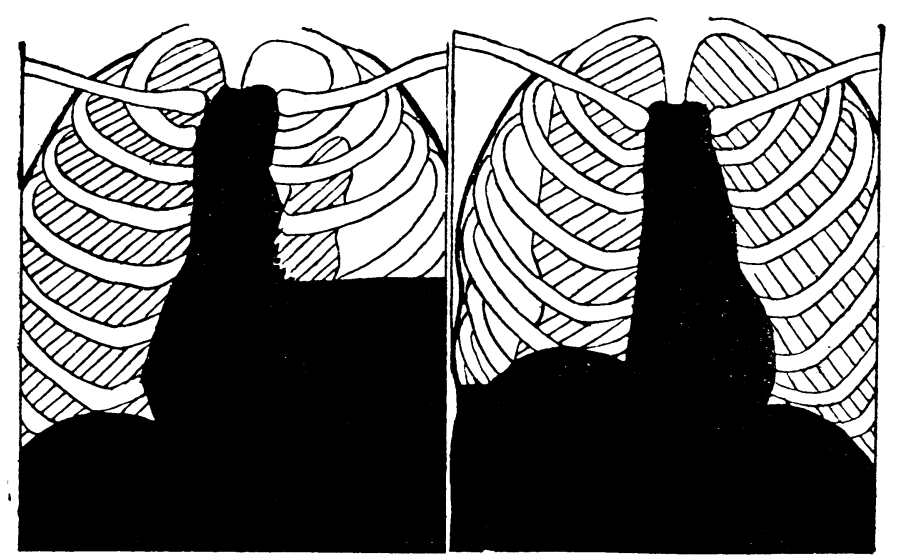

FIG. 1.

l:ai, :

FIG. 1.-T., 1,000 c.cm. fluid removed, $750 \mathrm{c.cm}$. air replaced. Fig. 2.-T. C., 2,710 Pressure $+4+2$ ,710 c.cm. fluid removed, 1,655 c.cm. oxygen repliticed. Pressure - $6-2$.

Now it is obvious that very different effects would have been produced in these cases by simple aspiration of $\mathbf{1 . 5}$ litres, without replacement, as permitted in the directions of all the quoted textbooks. Slight disturbance would have resulted in the second case, but it requires little imagination to realize what would have happened in the first chest. The shrunken collapsed lung would suddenly have been dragged open by a great negative pressure, the modiastinum would have been violently displaced towards the side of the vacuum, the pationt would have suffered immediate shock great pain and distress, and perhaps collapse. Any tuberculous focus in the lung would have been ruthlesily torn open and the discase spread far and wide by aspiration. The presence of the roplacing gas prevents the re-expansion of the lung (which occurs slowly as it is absorbed) and allows time for the healing of a pulmonary focus and for watching the pulse and temperature, so that a permanent pncumothorax may be maintained if the disease is found to be active in the lung. Oxygen is recommended if immediate re-expansion is desirable, but it seems to me that the longer period of rest following the slower absorption of air, is a distinct advantage.

\section{Drficulties of Techaigue}

I propose to consider now the difficulties of technique. The usual procedure recommended is that an aspirating trocar is introluced at the base of the effusion, and an

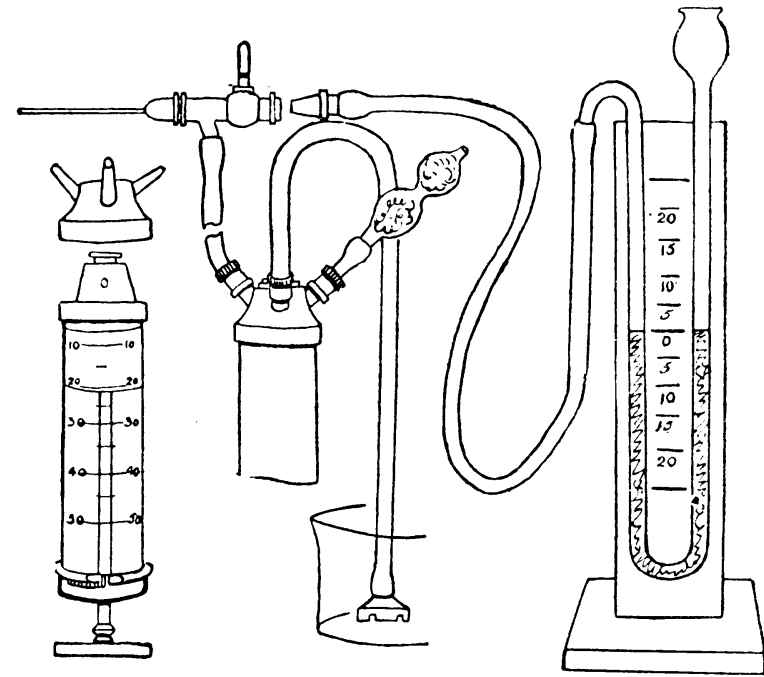

Fig. 3.--Rotanca syringe showing connexions with paticut, air filters, and fluid rectiver. The manometer ready to is plugged in.

syringe for blood transfusion. This syringe, manufactured by Messrs. Haselmeier of Stuttgart (and obtainable from Fannin and Co., 41, Grafton Street, Dublin), consists of a graduated 50 or $100 \mathrm{c} . \mathrm{cm}$. barrel with one outlet, which rotates inside a metal head with three ports (Fig. 3). The syringe can be put into communication with any one of these by merely rotating the barrel. It is thus possible to have a connexion with the chest, with a receiving receptacle, and with an air or oxygen container. A water manometer needle and tubing completes the apparatus, which can be used single-handed, and which turns the difficulty of the induction of the pneumothorax into a simple matter.

The working of the apparatus is familiar to everyone who has ever handled a syringe. With a very fine needle a few minims of local anaesthetic are injected under the skin in the posterior axillary line. The needle is then pushed in one to one and a half inches, and 1 c.cm. of anaesthetic is injected. It is then withdrawn half-way, and left in situ to mark the anaesthetic track. After waiting five to ten minutes to allow the pleura to become fully anaesthetized, the trocar is inserted and the fluid aspirated and ejected. Each $50 \mathrm{c} . \mathrm{cm}$. of fluid is replaced by $45 \mathrm{c} . \mathrm{cm}$. of air, which is drawn through sterile gauze 
filters and slowly injected into the thorax. (As the air expands when heated to body temperature by 10 per cent. of its volume, $45 \mathrm{c} . \mathrm{cm}$. are used to replace $50 \mathrm{c.cm}$.) When this has been done a few times the presence of a gas bubble can be made out by percussion in the upper part of the chest anteriorly. The skin and pleura are again anaesthetized over this, and a trocar connected with a water manometer is passed into it. The presence of the gas bubble prevents injury to the lung, and, as a rule, makes the entry no more difficult than a simple refill. The pressure is read and aspiration and air filling continued as before, until the chest is dry, keeping the pressure in the manometer at a constant figure.

It will be found that much less air than fluid is required to maintain this pressure, because of the expansion of the gas and the rising of the diaphragm when it is freed from the weight of the fluid. For this reason also it is not desirable to insert the aspirating trocar too low in the pleural sac, as the ascending diaphragm may obstruct it. The difficulties are few. A " dry tap" may occasionally be met with. This results from entering a band of adhesion or organizing tissue in the base. These are comparatively common in effusions that have stood for a long time. Pleural shock is prevented by careful anaesthetizing, and all pain, discomfort, and distress by replacing the fluid by gas as it is removed. There is no danger from cough, faintness, or oedema of the lung. Gas embolism is prevented by careful preliminary aspiration and the avoidance of a high positive pressure in the thorax.

This method entails the insertion of a second needle in the upper part of the chest, the advantage of which is that the intrapleural pressure may be watched and kept constant all through the operation.

A much simpler procedure may be carried out with one aspirating trocar only, replacing the fluid with two-thirds of its volume of air. When the chest is quite empty of fluid, and only the replacement air is being sucked through the syringe, the latter is half rotated-which seals off the chest-whilst a manometer is connected by a simple adapter to the end of the trocar, and the tap turned to put it into communication with the pleural cavity. The pressure is read, and if positive is adjusted by slow removal of air until a pressure between 0 and -4 is obtained. This method reduces gas replacement to its simplest term. It is entirely a single-handed procedure, and is within the capabilities of everyone who can use a syringe and has the minimum degree of manual dexterity.

If for any purpose it is desirable to employ oxygen, a rubber bag containing the gas can be attached to the air filter.

\section{PURULENT EFFUSIONS}

Tuberculous purulent effusions may be treated by gas replacement, oleothorax or gelatinothorax, or early thoracoplasty.

The rotanda syringe method is ideal for making an oleothorax. The chest is emptied of pus, which is replaced by oxygen ; with the patient lying on the sound side the procedure is, reversed. The oxygen is aspirated and the oil slowly injected.

Lastly, in certain cases of pneumococcal or streptococcal empyemas, total aspiration and oxygen replacement offers a very simple and adequate treatment. In these cases oxygen is used to promote expansion of the lung by its more rapid absorption, and a negative pressure as high as can be comfortably borne is maintained for the same purpose. The absence of any external opening is an immense advantage. Finally, the chest may be washed out and an effusion thinned by repeatedly pumping in and out Dakin's solution or any other antiseptic fluid.

\section{CONCLUSIONS}

1. Pleural effusions are essentially dangerous.

2. Current treatment adds to, rather than diminishes, these dangers.

3. A really satisf-ctory method of treatment does exist.

4. It has failed to achieve popularity through wrong approach to the problem and through difficulties of technique.

5. A method of overcoming these difficulties is described.

REFERENCES

${ }^{1}$ Burrell, L. S. T.: Modern Technique in Treatment, vol.iv, p. 208 ; British Medical Journal, April 11th, 1931, p. 620.

2 Norris and Landis: Diseases of the Chest, fourth edition, p. 646

3 Parker, R. W.: Lancet, 1882, i, 689 .

"Potain: Bull. de l'Académie de Méd., 1888, Second Series, xix, 537. ${ }_{5}$ Potain: Bull. de l'Académie de Méd., 1888, Second Series, xix, 537.
Burrell, L. S. T.: British Medical Journal, loc. cit.; Recent Advances in Pulmonary Tuberculosis, Churchill, 1929, p. 70.

\section{THE MEAN TEMPERATURE OF HEALTHY GIRLS}

BY

J. H. P. PATON, M.D.

MEMIBER OF THE STAFF OF THE JAMIES MIACKENZIE INSTITUTE FOR CLINICAL RESEARCH

In the Journal of May 28th, 1932, Lyon and Wallace ${ }^{1}$ point out that the temperature of afebrile hospital patients as recorded night and morning is slightly more than $1^{\circ}$ below the "normal" temperature reading $\left(98.4^{\circ} \mathrm{F}\right.$.). They state that " it is not unreasonable to assume, therefore, that if the temperature of a recumbent individual suddenly rises from $97^{\circ}$ to $98.4^{\circ} \mathrm{F}$. that individual is also slightly febrile, despite the fact that the temperature has not risen above the conventional limit."

\section{Details of Investigation}

The following observations, made in a large boarding school for girls, suggest that these conclusions are also true of healthy girls engaged in active life.

The information which I have to submit was obtained exclusively from records of girls of from 14 to 17 years of age. This limitation must be made perfectly clear because it may be injudicious to assume that the results are applicable to persons of different age or of the opposite sex. It is known, for example, that the temperature and pulse of younger children are less stable than those of older children, and it is possible that girls of 14 to 17 may differ in some degree from adults or from boys.

It is commonly assumed, for example, that the temperature of convalescents is usually subnormal. In the majority of cases, however, the convalescent reading is of the same order as that found in health as illustrated in Charts 1 and 2.

In both, the convalescent temperature is almost uniformly below $98^{\circ}$, and might therefore be considered subnormal but for the fact that it differs in no way from the reading obtained from the same individuals in health.

In particular, the so-called normal temperature $\left(98.4^{\circ} \mathrm{F}\right.$. or, according to some authors, $98.6^{\circ} \mathrm{F}$.) is so rare that, in my experience, its occurrence in adolescent girls always warrants a strong suspicion of ill-health.

On three occasions, for a continuous period of about a fortnight, a record was kept of the morning and evening temperatures of a group of healthy girls leading an active school life. The temperatures were all taken orally with thermometers certified by the National Physical Laboratory. Two precautions were observed throughoutnamely, that the records should not be taken $(a)$ within half an hour after meals, or $(b)$ within an hour of participation in an active game. Altogether 108 girls were 